\title{
Effect on gastric and duodenal mucosal prostaglandins of repeated intake of therapeutic doses of naproxen and etodolac in rheumatoid arthritis
}

\author{
A S Taha, S McLaughlin, P J Holland, R W Kelly, R D Sturrock, R I Russell
}

\begin{abstract}
The synthesis of gastric and duodenal mucosal prostaglandin $E_{2}$, prostaglandin $I_{2}$, and thromboxane $B_{2}$ during a 60 minute incubation of biopsy specimens, the degree of endoscopic and histological damage, and the antiinflammatory response were all studied after a four week, double blind study of therapeutic doses of two non-steroidal anti-inflammatory drugs, naproxen and etodolac, received by 27 patients with active rheumatoid arthritis (13 receiving naproxen, 14 etodolac). Prostaglandin values after treatment did not differ from the baseline levels when all the patients were analysed as one group. Subgroup analysis showed that naproxen suppressed gastric prostaglandin $E_{2}$ from a median of 29 to 9 $\mathrm{ng} / \mathrm{mg}$ protein, duodenal prostaglandin $\mathbf{E}_{2}$ from 34 to $11 \mathrm{ng} / \mathrm{mg}$, and duodenal prostaglandin $I_{2}$ from 62 to $15 \mathrm{ng} / \mathrm{mg}$ protein. No overall suppression occurred with etodolac. Also, on the second assessment patients receiving naproxen had lower gastric and duodenal prostaglandin $E_{2}$ and prostaglandin $I_{2}$, but higher values of duodenal thromboxane $B_{2}$, than patients receiving etodolac. Both drugs had comparable anti-arthritic activity and caused microscopic gastritis in similar proportions of patients. No correlation was detected between prostaglandin values and the mucosal damage which developed in seven patients receiving naproxen $(54 \%)$ and three receiving etodolac (21\%).

These findings indicate that, unlike naproxen, etodolac does not seem to affect gastric or duodenal prostaglandin synthesis; other mechanisms of injury need to be considered.
\end{abstract}

Gastroenterology Unit, Glasgow Royal Infirmary A S Taha

S McLaughlin

R I Russell

Centre for Rheumatic

Diseases, Glasgow Royal

Infirmary

R D Sturrock

MRC Unit for

Reproductive Biology,

Edinburgh

$P$ J Holland

${ }_{R}^{P}$ J Holland

Correspondence to:

Dr A S Taha,

Gastroenterology Unit

Gastroenterology Unit,

G31 2ER, Scotland.

Accepted for publication

18 July 1989
It has been increasingly recognised that nonsteroidal anti-inflammatory drugs (NSAIDs) and prostaglandins have opposite effects on the defensive mechanisms of the gastric mucosa. ${ }^{12}$ One theory suggests that NSAID induced damage is due to suppression of mucosal prostaglandin synthesis. ${ }^{34}$ Most knowledge in this field has come from animal work, ${ }^{3-7}$ or from studies of young, healthy, human volunteers given single doses or short term courses of aspirin or indomethacin. ${ }^{89}$ When patients with rheumatic disorders were studied ${ }^{10}$ basal values of the ability of gastroduodenal mucosa to synthesise prostaglandins were not known, and the precise nature of their disease was not adequately described.
Etodolac is a member of a new class of NSAIDs, the pyranocarboxylic acids; it has been reported to be better tolerated by the stomach than naproxen, ${ }^{11}$ a propionic acid derivative with established efficacy in arthritis, but both agents were reported to have a comparable anti-arthritic activity. ${ }^{12}$ An animal study suggested that the different effect of these two agents on the gastric mucosa might be due to the sparing of gastric prostaglandin synthesis by etodolac. ${ }^{13}$

The purpose of this prospective, double blind, single centre study was to assess the effect of four weeks' treatment with therapeutic doses of naproxen or etodolac in patients with active rheumatoid arthritis on gastroduodenal mucosal prostaglandin synthesis, anti-inflammatory activity, and endoscopic and histological changes.

Subjects, materials, and methods PATIENTS WITH RHEUMATOID ARTHRITIS

The patients studied were 18-70 years with active rheumatoid arthritis according to the criteria of the American Rheumatism Association. Patients receiving second line agents-gold, penicillamine, or hydroxychloroquine but not sulphasalazine-were included if the drug treatment had been started six or more months before the start of the study and the doses had been unchanged for the last two months. Sulphasalazine was excluded because $5-10 \%$ of its 5-aminosalicyclic acid component is absorbed, which might affect prostaglandin production, although there is no evidence for this. Subjects receiving NSAIDs underwent a washout period of at least five to seven days before receiving the study drugs, during which time paracetamol was used as an analgesic agent. Preliminary work at our units showed that there was no significant difference in gastric or duodenal mucosal prostaglandin synthesis between arthritic patients who had stopped receiving NSAIDs for four days and controls who were not receiving NSAIDs. Patients with abdominal complaints, a history of peptic ulceration, or any systemic diseases were excluded. Those taking cytotoxic agents, steroids, or ulcer healing drugs were also excluded.

STUDY DRUGS

Naproxen $500 \mathrm{mg}$ twice daily and etodolac 300 mg twice daily were given in a double blind, randomised design for a period of four weeks, 
with paracetamol used as a baseline analgesic. Compliance was checked by a tablet count.

\section{ASSESSMENTS}

Assessments were made on two visits-just before the start of the study and on completion four weeks later. They included a general medical history and examination, assessment of the activity of the rheumatoid arthritis, and endoscopy. Rheumatoid disease activity was assessed by measuring the erythrocyte sedimentation rate, grip strength $(\mathrm{mmHg})$, Ritchie articular index, duration of morning stiffness, and both the patients' and investigators' evaluation of the global condition. Endoscopy was performed after giving 5-15 mg diazepam intravenously. Endoscopic abnormalities were graded according to a $(0-5)$ scale modified from Lanza et al $^{14}: 0=$ normal; $1=$ any erythematous changes; 2 =submucosal haemorrhage; $3=$ single erosion; 4=multiple erosions; and 5=frank ulceration.

Patients showing abnormal endoscopic findings at the initial visit were not admitted to the study. On both visits biopsy specimens weighing 5-10 mg were taken from healthy looking mucosa in the gastric antrum and the first part of the duodenum for prostaglandin assays and for histology. All assessments were done under double blind conditions. Suitable patients were given the study drugs within 12 hours of completing the initial assessment.

\section{HISTOLOGY}

Specimens were fixed in formalin buffered saline, embedded in paraffin wax, and $5 \mu \mathrm{m}$ sections prepared for light microscopy. Sections were stained with haematoxylin and eosin. Histological appearances were broadly divided into mild or severe inflammation: mild inflammation referred to the presence of few inflammatory cells in the lamina propria, while severe inflammation meant that there was extensive inflammatory infiltration of the lamina propria, glands, and crypts. ${ }^{15}$

\section{PROSTAGLANDIN ASSAYS}

Biopsy specimens were taken and immediately frozen in liquid nitrogen and stored at $-70^{\circ} \mathrm{C}$. Each specimen was later thawed, weighed, and washed in $0.5 \mathrm{ml}$ of phosphate buffer for five minutes at room temperature to remove debris and prostaglandins induced by trauma. The supernatant was removed and specimens were incubated at $20^{\circ} \mathrm{C}$ for 30 minutes and at $37^{\circ} \mathrm{C}$ for another 30 minutes. Fresh phosphate buffer $(0.5 \mathrm{ml})$ was added at the start of each incubation step, and the supernatant removed at the end of each stage was mixed with an equal volume (1:1) of methyloximation agent, ${ }^{16}$ left overnight at room temperature, and stored at $4^{\circ} \mathrm{C}$ until needed for radioimmunoassay. After incubation at $20^{\circ} \mathrm{C}$ the biopsy specimens were incubated at $37^{\circ} \mathrm{C}$ to stimulate further prostaglandin synthesis. Prostaglandins were assayed in both incubates separately and their values summated. Prostaglandin $I_{2}$ and thromboxane $A_{2}$ were measured as their stable metabolites 6-oxo- prostaglandin $F_{1,}$ and thromboxane $B_{2}$ respectively.

Intra-assay variations were $14 \cdot 8 \%$ for prostaglandin $\mathrm{E}_{2}, 11 \cdot 0 \%$ for 6-oxo-prostaglandin $\mathrm{F}_{1 u}$, and $5 \cdot 0 \%$ for thromboxane $B_{2}$. Inter-assay variations were $13 \cdot 5-26 \%$ for prostaglandin $E_{2}$, $13.0 \%$ for 6-oxo-prostaglandin $F_{1 u}$, and $5.6 \%$ for thromboxane $B_{2}$. Cross reactions of the antisera were as follows: prostaglandin $\mathrm{E}_{2}$ (methyloximation agent) antiserum with prostaglandin $\mathrm{E}_{1} 53 \%$, prostaglandin $\mathrm{E}_{3} 31 \%$, prostaglandin $\mathrm{B}_{2} \quad 0 \cdot 2 \%$, 15-oxo-prostaglandin $\mathrm{E}_{2} \quad 0 \cdot 25 \%$. 6-Oxo-prostaglandin $\mathrm{F}_{1 \mathrm{le}}$ (methyloximation agent) antiserum with thromboxane $\mathrm{B}_{2} 0.02 \%$, prostaglandin $E_{2} \quad 0.01 \%$, prostaglandin $E_{1}$ $0.01 \%$. Thromboxane $B_{2}$ antiserum with prostaglandin $\mathrm{D}_{2} \quad 0.02 \%$, 6-oxo-prostaglandin $E_{1} 0.02 \%$, prostaglandin $E_{2} 0.02 \%$. The sensitivity of prostaglandin assays (as defined by the amount distinguishable from zero with $95 \%$ confidence limit) was $2 \mathrm{pg}$ in all assays. Other details of prostaglandin cross reactions, the sensitivity of prostaglandin assays, intra-assay and interassay precisions have been described previously. ${ }^{16-18}$ The protein content of each biopsy specimen was measured, ${ }^{19}$ and the results of prostaglandin synthesis are expressed in $\mathrm{ng}$ prostaglandin $/ \mathrm{mg}$ protein after a total of 60 minutes' incubation.

\section{STATISTICAL ANALYSES}

Statistical analyses were carried out with the Wilcoxon signed ranks and the Mann-Whitney tests, where appropriate. $p$ Values of less than 0.05 were regarded as significant. Correlation between prostaglandin values and endoscopic scores was tested using Spearman's rank correlation coefficient.

Informed consent was obtained from patients, and the study was approved by the local ethical committee.

\section{Results}

Twenty seven patients completed the study; 13 (nine women, four men), median age 60 years, were found to have been receiving naproxen, and 14 (10 women, four men), median age 50 , etodolac. Three further patients were not entered into the study because their initial endoscopy was abnormal and two other patients dropped out before completing the study owing to protocol violations. In the group receiving naproxen six patients smoked, nine were receiving second line drugs, and 10 had previous exposure to NSAIDs, compared with seven, eight, and 11 patients in the etodolac group respectively. Compliance was good and comparable in both groups (median of $89 \%$ of naproxen tablets and $87 \%$ of etodolac tablets provided were taken), though patients receiving etodolac used less paracetamol.

\section{PROSTAGLANDIN SYNTHESIS}

Baseline values were similar in both groups. When all rheumatoid patients were considered as one group there was no significant change in gastric or duodenal prostaglandin values before 
Table 1: Gastric and duodenal prostaglandin $E_{2}$, median (interquartile ranges), $n g / m g$ protein, at baseline and after non-steroidal anti-inflammatory drug treatment

\begin{tabular}{|c|c|c|c|c|}
\hline \multirow[t]{2}{*}{ Subjects } & \multicolumn{2}{|l|}{ Baseline } & \multicolumn{2}{|l|}{4 Weeks } \\
\hline & Gastric & Duodenal & Gastric & Duodenal \\
\hline $\begin{array}{l}\text { All rheumatoid patients }(n=27) \\
\text { Patients receiving naproxen }(n=13) \\
\text { Patients receiving etodolac }(n=14)\end{array}$ & $\begin{array}{l}29 \\
(23-41) \\
29 \\
(24-65) \\
29 \\
(16-35)\end{array}$ & $\begin{array}{l}28 \\
(17-39) \\
34 \\
(21-39) \\
18 \\
(15-35)\end{array}$ & $\begin{array}{l}20 \\
(9-76) \\
9 \\
(4-17) \\
64 \\
(21-101)\end{array}$ & $\begin{array}{l}19 \\
(10-33) \\
11 \\
(6-16) \\
29 \\
(20-42)\end{array}$ \\
\hline
\end{tabular}

Significant drop: "p $<0.01$ (compared with baseline values in the naproxen group and with values after treatment in patients receiving etodolac).

Table 2: Gastric and duodenal prostaglandin $I_{2}$ (6-oxo-prostaglandin $\left.F_{1,1}\right)$, median (interquartile range), ng/mg protein, at baseline and after non-steroidal anti-inflammatory drug treatment

\begin{tabular}{|c|c|c|c|c|}
\hline \multirow[t]{2}{*}{ Subjects } & \multicolumn{2}{|l|}{ Baseline } & \multicolumn{2}{|l|}{4 Weeks } \\
\hline & Gastric & Duodenal & Gastric & Duodenal \\
\hline All rheumatoid patients $(n=27)$ & 12 & 50 & 18 & 28 \\
\hline Patients receiving naproxen $(n=13)$ & $\begin{array}{l}(8-17) \\
11\end{array}$ & $\begin{array}{l}(28-84) \\
62\end{array}$ & $(2-37)$ & $\begin{array}{l}(11-42) \\
15\end{array}$ \\
\hline Patients receiving etodolac $(n=14)$ & $\begin{array}{l}(7-14) \\
15 \\
(9-18)\end{array}$ & $\begin{array}{c}(34-86) \\
39 \\
(16-63)\end{array}$ & $\begin{array}{l}(1-27) \\
23 \\
(13-42)\end{array}$ & $\begin{array}{c}(2-32) \\
40 \\
(29-44)\end{array}$ \\
\hline
\end{tabular}

Significant drop: ${ }^{*} \mathrm{p}<0.05$ (compared with baseline values in the naproxen group and with gastric and duodenal values after treatment in patients receiving etodolac).

Table 3: Gastric and duodenal thromboxane $B_{2}$, median (interquartile ranges), ng/mg protein, at baseline and after non-steroidal anti-inflammatory drug treatment

\begin{tabular}{|c|c|c|c|c|}
\hline \multirow[t]{2}{*}{ Subjects } & \multicolumn{2}{|l|}{ Baseline } & \multicolumn{2}{|l|}{+ Weeks } \\
\hline & Gastric & Duodenal & Gastric & Duodenal \\
\hline $\begin{array}{l}\text { All rheumatoid patients }(n=27) \\
\text { Patients receiving naproxen }(n=13) \\
\text { Patients receiving etodolac }(n=14)\end{array}$ & $\begin{array}{l}33 \\
(23-61) \\
35 \\
(23-60) \\
33 \\
(21-61)\end{array}$ & $\begin{array}{l}36 \\
(21-41) \\
36 \\
(28-45) \\
27 \\
(21-38)\end{array}$ & $\begin{array}{c}38 \\
(24-48) \\
40 \\
(28-45) \\
34 \\
(22-48)\end{array}$ & $\begin{array}{l}31 \\
(20-41) \\
35 \\
(27-42) \\
22 \\
(14-41)\end{array}$ \\
\hline
\end{tabular}

Significant rise: $p<0.05$ (compared with etodolac)

or after NSAID treatment. Significant differences became noticeable when patients were classified according to whether they had received naproxen or etodolac (tables 1-3); gastric prostaglandin $\mathrm{E}_{2}$, duodenal prostaglandin $\mathrm{E}_{2}$ and prostaglandin $\mathrm{I}_{2}$ were all suppressed by naproxen. Etodolac seemed to have no effect on prostaglandin concentrations. In addition, compared with etodolac patients on the second assessment, naproxen patients had lower gastric and duodenal prostaglandin $E_{2}$ and prostaglandin $I_{2}$ but higher values of duodenal thromboxane $B_{2}$.

ANTI-ARTHRITIC ACTIVITY

Table 4 shows the improvement in the indices of rheumatoid disease activity; all variables improved after treatment but not necessarily to a significant degree, apart from the duration of morning stiffness $(p<0.001)$ and the articular index $(p<0.05)$. The overall results indicate that in this small group of patients naproxen and etodolac had similar anti-inflammatory efficacy.

ENDOSCOPIC AND HISTOLOGICAL CHANGES

The second endoscopy was abnormal in seven patients receiving naproxen $(54 \%)$ with a median score of $2(0-4)$, (interquartile ranges), compared with three patients receiving etodolac $(21 \%)$ and a score of $0(0-1)(p<0 \cdot 05)$. Lesions developed

Table 4: Duration of morning stiffness, grip strength, articular index, and erythrocyte sedimentation (ESR) before and after treatment: median and interquartile ranges

\begin{tabular}{|c|c|c|c|c|c|c|}
\hline \multirow[t]{2}{*}{ Indices of activity } & \multicolumn{2}{|c|}{$\begin{array}{l}\text { All rheumatoid patients } \\
(n=27)\end{array}$} & \multicolumn{2}{|c|}{$\begin{array}{l}\text { Naproxen group } \\
(n=13)\end{array}$} & \multicolumn{2}{|c|}{$\begin{array}{l}\text { Etodolac group } \\
(n=14)\end{array}$} \\
\hline & Baseline & 4 Weeks & Baseline & 4 Weeks & Baseline & 4 Weeks \\
\hline Duration of morning stiffness (min) & $\begin{array}{l}60 \\
(60-120)\end{array}$ & $\begin{array}{l}30^{*} \\
(5-60)\end{array}$ & $\begin{array}{l}90 \\
(60-150)\end{array}$ & $\begin{array}{l}50 \\
(17-90)\end{array}$ & $\begin{array}{l}60 \\
(48-105)\end{array}$ & $\begin{array}{l}30 \\
(12-55)\end{array}$ \\
\hline $\begin{array}{l}\text { Grip strength }(\mathrm{mmHg}) \\
\text { Right hand } \\
\text { Left hand } \\
\text { Articular index } \\
\text { ESR }\end{array}$ & $\begin{array}{l}74 \\
(60-105) \\
80 \\
(68-116) \\
13 \\
(10-19) \\
22 \\
(7-39)\end{array}$ & $\begin{array}{l}83 \\
(65-135) \\
94 \\
(72-144) \\
8 \\
(5-11) \\
17 \\
(8-33)\end{array}$ & $\begin{array}{l}74 \\
(60-102) \\
77 \\
(65-129) \\
16 \\
(10-22) \\
23 \\
(10-36)\end{array}$ & $\begin{array}{l}102 \\
(60-154) \\
93 \\
(67-174) \\
10 \\
(7-12) \\
17 \\
(9-34)\end{array}$ & $\begin{array}{l}76 \\
(59-126) \\
88 \\
(67-130) \\
13 \\
(9-18) \\
18 \\
(7-41)\end{array}$ & $\begin{array}{l}81 \\
(71-120) \\
96 \\
(70-139) \\
6 \\
(3-11) \\
16 \\
(5-35)\end{array}$ \\
\hline
\end{tabular}

Significant improvement: ${ }^{*} \mathrm{p}<0.001 ;{ }^{*} \mathrm{p}<0.01 ;{ }^{*} \mathrm{p}<0.05$. 
in the stomach in all 10 cases (seven naproxen, three etodolac) but one patient receiving naproxen had them in both the stomach and the duodenum. Only three patients (naproxen) developed upper abdominal complaints, and the rest were all asymptomatic. Prostaglandins were not suppressed in the three patients with endoscopic abnormalities due to etodolac. As mentioned above, comparable numbers of patients took other NSAIDs before receiving either naproxen or etodolac. Prior exposure to NSAIDs did not seem to affect the side effects due to the study drugs, possibly because of the washout period. Only seven patients (five naproxen, two etodolac) out of 21 (33\%) previously receiving NSAIDs developed endoscopic damage on completion of the study. Prostaglandin values in such patients were not significantly different from those of other members of their respective groups. The number of patients with severe inflammation in their gastric biopsy specimens rose from three $(23 \%)$ to $10(77 \%)$ after taking naproxen, and from four $(29 \%)$ to $11(79 \%)$ after etodolac treatment. There was no correlation between prostaglandin values and the degree of gastric endoscopic damage $(r=-0.3196$ for prostaglandin $E_{2},-0.3793$ for prostaglandin $I_{2}$, and -0.2339 for thromboxane $B_{2}$ in the entire population of rheumatoid patients). Also, no significant correction was found between the prostaglandin $E_{2} /$ thromboxane $B_{2}$ ratio and the endoscopic scores $(r=-0 \cdot 2495)$. Both gastric and duodenal prostaglandin $\mathrm{E}_{2} /$ thromboxane $\mathrm{B}_{2}$ ratios were significantly higher in patients receiving etodolac than in those who took naproxen $(p<0 \cdot 005)$. From these results it seems that there should be some form of negative correlation between endoscopic scores and prostaglandin $E_{2} /$ thromboxane $B_{2}$ ratios as patients receiving naproxen appear to have lower ratios and higher scores. This cannot be proved, however, as no correlations were significant.

\section{Discussion}

This study shows that, unlike naproxen, etodolac does not suppress gastric or duodenal prostaglandin synthesis. In this respect these results disagree with most of the available data obtained from studies on gastric prostaglandins in patients with rheumatic diseases or those receiving regular NSAID treatment; such studies have shown that the NSAIDs tested do suppress gastric prostaglandins. ${ }^{10} 20$ The effects of individual NSAIDs were not known in those reports, however, baseline prostaglandins were not measured, and the number of patients taking the same agent was small.

Patients receiving naproxen had both a greater number of endoscopic abnormalities and lower prostaglandin values. Possibly, these two events were interrelated, but we, like others, ${ }^{8}$ were unable to show a correlation between the endoscopic scores and prostaglandin values. Gastritis $^{20}$ does not adequately explain the sparing of prostaglandin by etodolac as inflammation was present in similar numbers of patients who took either agent. The significance of this gastritis is unclear; it was not evident on endoscopic examination and was only shown by histology.

Possibly, agents like etodolac may be selective in their effects on various tissues and different types of prostaglandins. Such an effect was previously described with salicylic acid, which caused preferential reduction in prostaglandin $\mathrm{E}_{2}$ in sheep vesicular tissue, whereas indomethacin suppressed all classes of prostaglandins. $^{21}$

The fact that prostaglandins were not suppressed in patients who developed endoscopic abnormalities due to etodolac may mean that the mucosa recovered its capacity to synthesis prostaglandin before full healing of erosions, though we have not shown that such capacity was lost to begin with, or that mechanisms other than prostaglandin deficiency were involved in causing gastric damage: in theory, these could include increased mucosal permeability, ${ }^{22}$ interference with active ion transport, ${ }^{23}$ redistribution of mucosal blood flow, ${ }^{24}$ capillary stasis, ${ }^{25}$ or interference with the mucus layer. ${ }^{26}$

Little is known about the duodenal mucosal prostaglandin response to the intake of NSAIDs as most studies have concentrated on their effect on the gastric mucosa, ${ }^{35689}$ possibly owing to the fact that the stomach is more commonly affected by NSAIDs than the duodenum as shown by this study and by others. ${ }^{27}$ Like one of the previous studies on patients with duodenal ulcers, ${ }^{28}$ our results may suggest that the duodenal mucosal potential to synthesise prostaglandin $\mathrm{I}_{2}$ becomes limited in the presence of ulceration or when subjected to naproxen. Duodenal prostaglandin $\mathrm{E}_{2}$ was also suppressed in our patients taking naproxen, but not in those of Hillier et al, ${ }^{28}$ the difference probably being due to the fact that their patients did not take NSAIDs. It is also interesting to find that patients who took naproxen had higher values of thromboxane $B_{2}$ (the stable metabolite of thromboxane $\mathrm{A}_{2}$ ) than those receiving etodolac. Animal studies have suggested that vasoconstriction with thromboxane $\mathrm{A}_{2}$ induces ulceration of the gastric mucosa, ${ }^{29}$ and that the selective inhibition of its synthesis results in gastric mucosal protection. ${ }^{30}$ The effect of thromboxane $\mathrm{A}_{2}$ on the duodenal mucosa was not clarified by those studies. We found that both gastric and duodenal prostaglandin $\mathrm{E}_{2} /$ thromboxane $B_{2}$ ratios were higher in patients taking etodolac than in those receiving naproxen. The significance of this is not fully clear but it may explain, at least in part, the greater damaging effects of naproxen, though we could not show a significant correlation between the prostaglandin $E_{2} /$ thromboxane $B_{2}$ ratio and the endoscopic scores.

In conclusion, after four weeks of regular intake in therapeutic doses, naproxen suppressed gastric prostaglandin $\mathrm{E}_{2}$, duodenal prostaglandin $\mathrm{E}_{2}$ and prostaglandin $\mathrm{I}_{2}$, while etodolac did not. At the same time etodolac caused a lesser degree of endoscopic damage than naproxen; this may be related to their different effects on prostaglandins, though there was no correlation between prostaglandin values and endoscopic scores. If it is assumed that more 
NSAIDs are assessed along the same lines as our study and would behave similarly to either naproxen or etodolac, our results may indicate that not all NSAIDs suppress gastric or duodenal prostaglandins. Other modes of interaction between NSAIDs and the gastroduodenal mucosa need to be investigated.

We are very grateful to Wyeth Laboratories for providing the study drugs and financial support. We also thank Miss Margare Black for her secretarial assistance.

1 Domschke S, Domschke W. Gastroduodenal damage due to drugs, alcohol and smoking. Clin Gastroenterol 1984; 13 : 405-37.

2 Robert A. Cytoprotection by prostaglandins. Gastroenterologv 1979; 77: 761-7.

3 Main I H, Whittle B J. Investigation of the vasodilator and antisecretory role of prostaglandins in the rat gastric mucosa by use of non-steroidal anti-inflammatory drugs. $\mathrm{Br} \mathcal{F}$ Pharmacol 1975; 53: 217-24.

4 Konturek S J, Obtulowicz W, Sito E, Oleksy J, Wilkon S, Kiec-Dembinska A. Distribution of prostaglandins in gastric and duodenal mucosa of healthy subjects and duodenal ulcer patients; effect of aspirin and paracetamol. Gut 1981; 22: 283-9.

5 Whittle B J R, Higgs G A, Eakins K E, Moncada S, Vane $J$ R. Selective inhibition of prostaglandin production in inflammatory exudates and gastric mucosa. Nature 1980; 284: $271-3$.

6 Ligumsky M, Golanska E M, Hansen D G, Kauffman G L. Aspirin can inhibit gastric mucosal oxygenase without causing lesions in rat. Gastroenterology 1983; 84: 756-61.

7 Whittle B J R. Temporal relationship between cyclo-oxygenase inhibition as measured by prostaglandin biosynthesis and the gastrointestinal damage induced by indomethacin in the rat. Gastroenterology 1981; 80: 94-8.

8 Redfern J S, Lee E, Feldman M. Effects of indomethacin on gastric mucosal prostaglandins in humans, correlation with mucosal damage. Gastroenterology 1987; 92: 969-77.

9 Konturek S J, Obutlowicz W, Kwiecien N, Oleksy J. Generation of prostaglandins in gastric mucosa of patients Generation of prostaglandins in gastric mucosa of patients with peptic ulcer disease: effect of non-steroidal antiinflammatory com

10 Rachmilewitz D, Ligumsky M, Fich A, Goldin E, Eliakim A, Karmeli F. Role of endogeneous gastric prostanoids in the pathogenesis and therapy of duodenal ulcer. Gastroenterolog $v$ 1986; 90: 963-9.

11 Lanza F, Rack M F, Lynn M, Wolf J, Sanda M. An endoscopic comparison of the effect of etodolac, indometha-
cin, ibuprofen, naproxen and placebo on the gastrointestinal mucosa. F Rheumatol 1987; 14: 338-41.
12 Waltham-Weeks C D. Etodolac versus naproxen in rheumatoid arthritis: a double-blind crossover study. Curr Med Res Opin 1987; 10: 540-7

13 Lee D, Dvornik D. Etodolac: effect on prostaglandin concentrations in gastric mucosa of rats. Life Sci 1985; 36: $1157-62$.

14 Lanza F, Panagides J, Salom I L. Etodolac compared with aspirin: an endoscopic study of the gastrointestinal tract of aspirin: an endoscopic study of the gastrointestinal trac

15 Whitehead R, Truelove S C, Gear M W. The histological diagnosis of chronic gastritis in fiberoptic gastroscope biopsy specimens. $\mathcal{F}$ Clin Pathol 1972; 25: 1-11.

16 Kelly $R$ W, Deam $S$, Cameron $M$ J, Seamark $R$ F. Measurement by radioimmunoassay of prostaglandins as their methyloximes. Prostaglandins Leukotrienes Med 1986; 24: $1-14$.

17 Kelly R W, Healy D L, Cameron M J, Cameron I T, Baird D T. The stimulation of prostaglandin production by two antiprogesterone steroids in human endometrial cells. $\mathcal{F}$ Clin Endocrinol Metab 1986; 62: 1116-23.

18 Grant H W, Palmer K R, Kelly R W, Wilson N H. Misiewic\% J J. Dietary linoleic acid, gastric acid and prostaglandin secretion. Gastroenterology 1988; 94: 955-9.

19 Lowry O H, Rosebrough N J, Farr A L, Randall R J. Protein measurements with the folin phenol reagent. F Biol Chem 1951; 193: 265-75.

20 Hawkey C J. Synthesis of prostaglandin E2, thromboxane B2 and prostaglandin catabolism in gastritis and gastric ulcer. Gut 1986; 27: 1484-92.

21 Maddox I S. The role of copper in prostaglandin production. Biochim Biophys Acta 1973; 306: 74-81.

22 Smith B M, Skillman J J, Edwards G, Silen W. Permeability of the human gastric mucosa. Alteration by acetylsalicylic acid and ethanol. $N$ Engl f Med 1971; 285: 716-21.

23 Stern A I Hogan D L Isenberg J I A new method for quantitation of ion fluxes across in vivo human gastric quantitation of ion fluxes across in vivo human gastric mucosa: effect of aspirin, ethanol and
tions. Gastroenterology 1984;86: 60-70.

24 Ashley S W, Sonnenschein L A, Cheung L Y. Focal gastric mucosa blood flow at the site of aspirin-induced ulceration. Am f Surg 1985; 149: 53-9.

25 Rosam A C, Wallace J L, Whittle B J R. Potent ulcerogenic actions of platelet-activating factor on the stomach. Nature 1986; 319: 54-6.

26 Turner N C, Martin G P, Marriott C. The influence of native porcine gastric mucus gel on hydrogen ion diffusion: the effect of potentially ulcerogenic agents. F Pharm Pharmacol 1985; 37: 776-80.

27 Duggan J M, Dobson A J, Johnson H, Fahey P. Peptic ulcer and non-steroidal anti-inflammatory agents. Gut 1986; 27 . and non-ste.

28 Hillier K, Smith C L, Jewell R, Arthur M J P, Ross G. Duodenal mucosa synthesis of prostaglandins in duodenal ulcer disease. Gut 1985; 26: 237-40.

29 Whittle J R, Kauffman G L, Moncada S. Vasoconstriction with thromboxane $A_{2}$ induces ulceration of the gastric mucosa. Nature 1981; 292: 472-4

30 Walt, R P, Kemp R T, Filipowicz B, Davies J G, Bhaskar N K, Hawkey C J. Gastric mucosal protection with selective inhibition of thromboxane synthesis. Gut 1987; 28: 541-4. 